\title{
Desempenho de semeadora-adubadora utilizando-se dois mecanismos rompedores e três pressões da roda compactadora
}

\author{
André Koakoski(1), Cristiano Márcio Alves de Souza ${ }^{(1)}$, Leidy Zulys Leyva Rafull(1), Luiz Carlos Ferreira de Souza(1) \\ e Elton Fialho dos Reis ${ }^{(2)}$
}

\begin{abstract}
(1) Universidade Federal da Grande Dourados, Fac. de Ciências Agrárias, Caixa Postal 533,CEP 79804-970 Dourados, MS. E-mail: andrekoakoski@bol.com.br, csouza@ufgd.edu.br, zulys@ufgd.edu.br, Icfsouza@ceud.ufms.br(2)Universidade Estadual de Goiás, Campus de Anápolis, Caixa Postal 459, CEP 75110-000 Anápolis, GO. E-mail: fialhoreis@ibest.com.br
\end{abstract}

\begin{abstract}
Resumo - O objetivo deste trabalho foi estudar o efeito de diferentes mecanismos rompedores e níveis de pressões aplicadas pela roda compactadora sobre o desempenho de uma semeadora-adubadora na implantação da cultura de soja, em plantio direto sob três teores de água no solo. O experimento foi montado em esquema de parcelas subsubdivididas, em que as parcelas foram constituídas pelos três teores avaliados de água no solo $\left(0,22,0,24\right.$ e $\left.0,26 \mathrm{~kg} \mathrm{~kg}^{-1}\right)$, as subparcelas por dois mecanismos rompedores (facão e disco duplo) e as subsubparcelas por três níveis de pressões aplicadas pela roda compactadora $(12,2,18,5$ e 24,1 kPa), com três repetições, em um delineamento de blocos ao acaso. Foram analisadas a distância entre sementes, a profundidade de deposição, a porosidade, o índice de velocidade de emergência, a emergência a campo e a resistência do solo à penetração. $\mathrm{O}$ mecanismo rompedor do tipo facão proporciona maior profundidade de plantio e porosidade do solo, menor distância entre sementes e menor resistência do solo à penetração. A pressão da roda compactadora influencia a emergência de plântulas a campo, quando é usado o rompedor do tipo facão. O teor de água influencia a profundidade de deposição e distância entre sementes, o índice de velocidade de emergência e a resistência do solo à penetração.
\end{abstract}

Termos para indexação: soja, plantio direto, umidade de semeadura.

\section{Performance of seeder-fertilizer using two furrow opening mechanism and three loads on soil firming mechanism}

\begin{abstract}
The objective of this work was to study the effect of different furrow opening mechanism and levels of load applied to soil firming mechanism on the initial development of soybean, in no-till system under different soil moisture. A split-split-plot experiment was used, in which the main treatments were three soil water contents $\left(0.22,0.24 \mathrm{e} 0.26 \mathrm{~kg} \mathrm{~kg}^{-1}\right)$, split-plots were two types of furrow opening mechanisms (furrow plough and double disk), and split-split-plots were three levels of load applied to soil firming mechanism $(12.2,18.5$ and $24.1 \mathrm{kPa})$, using a randomized block design, with three replications. Distance between seeds, depth of seed allocation, soil porosity around the seed, emergence speed index, seedling emergence on field and soil resistance to penetration were analyzed. The furrow plough type of soil opening mechanism resulted in deeper seed allocation, higher soil porosity around the seed, smaller distance between seeds and smaller soil resistance to penetration. The pressure on the soil firming mechanism influences seedling emergence on field, when the furrow plough is used. The soil moisture influences the seed allocation and distance between seeds, the emergence speed index and the soil resistance to penetration.
\end{abstract}

Index terms: soybean, no-till, sowing moisture.

\section{Introdução}

As características das máquinas utilizadas no plantio e o estado físico do solo precisam ser levados em consideração para que se consiga alcançar os benefícios esperados no sistema de plantio direto (SPD), como desenvolvimento inicial adequado e alta produtividade da cultura.
Quando se utiliza diferentes mecanismos de abertura de sulco, como disco duplo e haste sulcadora do tipo facão, espera-se que ocorram diferenças na relação solosemente e na qualidade da semeadura (Reis et al., 2004). Entretanto, devido à grande diversidade de solos encontrados nas diferentes regiões do país, é inviável que uma máquina possibilite, em todos os casos, um bom contato do solo com a semente. 
A semeadora deve deixar o solo diretamente sobre as sementes, solto o suficiente para facilitar a emergência da plântula. Alguns autores comentam que a compactação acima da capacidade de suporte do solo, ao redor da semente, pode provocar impedimentos à germinação (Kondo \& Dias Júnior, 1999).

O formato do elemento compactador e a pressão que esse elemento exerce sobre o solo são muito relevantes para um bom contato do solo com a semente (Hummel et al., 1981). A compactação do solo, provocada pela ação das máquinas, interfere no sistema radicular, provocando modificações no seu desenvolvimento em profundidade. Segundo Queiroz-Voltan et al. (2000), em solos compactados, as raízes das plantas não utilizam adequadamente os nutrientes disponíveis.

Uma condição fundamental para a emergência das sementes é o teor de água do solo. A semente tem que atingir a umidade suficiente para germinar e iniciar o crescimento radicular. Para isso, é necessário não apenas que o teor de água do solo seja adequado, mas que a relação solo-água-semente, que é diretamente influenciada pela operação de semeadura, seja favorável (Reis et al., 2006). Outro fator que interfere na emergência das sementes é a profundidade em que são depositadas no sulco de semeadura. Se a profundidade for maior que a necessária para a emergência, a plântula irá levar mais tempo para emergir, permanecendo por mais tempo exposta ao ataque de pragas presentes no solo. Além disso, uma profundidade excessiva pode inviabilizar a germinação.

A distribuição uniforme das sementes na linha de semeadura também contribui para um bom desenvolvimento do estande inicial (Kurachi et al., 1989). Sementes muito próximas umas das outras acabam competindo entre si por água e nutrientes do solo.

Segundo Reis et al. (2003), em decorrência do grande número de fatores e variáveis que envolvem o processo de plantio, a pesquisa de campo com máquinas agrícolas encontra dificuldade quando se pretende estudar a interação máquina-solo-planta.

A região centro-sul do Estado de Mato Grosso do Sul tem aumentado o uso do sistema plantio direto, e o fato de a maioria das áreas apresentar solos muito argilosos tem dificultado o bom desempenho das semeadoras. Nas áreas com boa cobertura do solo, o uso de semeadoras equipadas com facão, na maioria das vezes, provoca o rastelamento da palha, e quando equipadas com disco de corte, é comum a distribuição superficial das sementes, o que dificulta a obtenção de um adequado estande inicial das culturas.
Este trabalho objetivou estudar o efeito de dois mecanismos rompedores e três níveis de pressões aplicadas pela roda compactadora, sobre o desempenho de uma semeadora-adubadora na implantação da cultura da soja, em plantio direto sob três teores de água no solo.

\section{Material e Métodos}

O trabalho foi realizado na Faculdade de Ciências Agrárias da Universidade Federal da Grande Dourados e na Empresa Sementes Guerra, localizadas no Município de Dourados, MS (latitude 22 ${ }^{\circ} 13^{\prime} 16^{\prime \prime S}$, longitude $54^{\circ} 17^{\prime} 1$ "W e altitude de $430 \mathrm{~m}$ ), na safra 2005/2006. O clima regional, classificado pelo sistema internacional de Köppen, é do tipo Cwa, clima úmido e inverno seco, com precipitação média anual de $1.500 \mathrm{~mm} \mathrm{e}$ temperatura média anual de $22^{\circ} \mathrm{C}$. Os estudos foram realizados em solo classificado como Latossolo Vermelho distroférrico, textura muito argilosa $(65,3 \%$ de argila, $17,4 \%$ de silte e $17,3 \%$ de areia), classe representativa da maioria dos solos do centro-sul do Estado de Mato Grosso do Sul e com declividade média de $2 \%$.

$\mathrm{Na}$ área experimental, cultivada no SPD há dez anos, havia restos culturais de aveia, utilizada como cultura antecessora. A área foi dessecada com aplicação de glyphosate, à dosagem de $5,0 \mathrm{~L} \mathrm{ha}^{-1}$ do produto comercial, com um volume de calda de $300 \mathrm{~L} \mathrm{ha}^{-1}$.

Para fins de caracterização das parcelas experimentais foi realizada a análise química do solo na profundidade de 0 a $20 \mathrm{~cm}$ (Embrapa, 1997). Resultados médios obtidos nas análises do solo estão apresentados na Tabela 1. A densidade do solo era de 1,28 $\pm 0,11 \mathrm{Mg} \mathrm{m}^{-3}$. O lote de sementes de soja (Glycine max (L.) Marrill), variedade Codetec-202, apresentava 97\% de germinação.

Os testes foram realizados com o uso de uma semeadora-adubadora PC 2123, com três linhas de plantio, com espaçamento de $0,45 \mathrm{~m}$ entre linhas, e massa total de $640 \mathrm{~kg}$, considerando os carregamentos de adubo e sementes. A máquina, montada no sistema de engate de três pontos, apresenta mecanismos de simples funcionamento e pequeno porte, e é recomendada para atender às necessidades de pequenas e médias propriedades rurais. É constituída, basicamente, por disco liso de corte de palhada, conjunto distribuidor de fertilizantes, dosador de sementes do tipo disco alveolado, com regulagem feita por meio de troca de engrenagens e acionado por pneus de tração. 
$\mathrm{Na}$ abertura do sulco, visando a colocação das sementes e fertilizante, utilizaram-se dois mecanismos: rompedores do tipo facão e disco duplo. A roda compactadora utilizada foi do tipo roda metálica lisa em forma de V.

A semeadora-adubadora foi tracionada por um trator, modelo MF265 4x2, com potência nominal de $48 \mathrm{~kW}$ $(61 \mathrm{cv})$ no motor a $2.000 \mathrm{rpm}$. A velocidade foi de $5,3 \mathrm{~km} \mathrm{~h}^{-1}$, dentro da faixa indicada para operação de semeadura (Oliveira et al., 2000).

Foram determinados os níveis de pressões aplicadas sobre o solo $(12,2,18,5$ e $24,1 \mathrm{kPa})$ por meio de uma célula de carga, modelo Z250, com capacidade de $2,45 \mathrm{kN}$. A célula de carga foi acoplada à roda compactadora da semeadora por meio de um suporte fixo. A pressão da roda compactadora sobre o solo foi determinada pela relação entre a força aplicada sobre o solo e a área de contato da roda.

As três pressões aplicadas sobre o solo pela roda compactadora correspondem às posições da regulagem do sistema de molas existentes na própria semeadoraadubadora. A pressão de $12,2 \mathrm{kPa}$ resulta da distensão de toda a mola, a de $18,5 \mathrm{kPa}$ corresponde à metade da regulagem e a de $24,1 \mathrm{kPa}$ se obtém com toda a mola comprimida.

A semeadura foi realizada nos teores de água do solo de $0,22,0,24$ e $0,26 \mathrm{~kg} \mathrm{~kg}^{-1}$. O teor de água foi determinado pelo método gravimétrico (método padrão de estufa), de acordo com a relação entre a massa de água e a massa do solo seco a $105^{\circ} \mathrm{C}$ (Embrapa, 1997).

A semeadora-adubadora foi previamente regulada para distribuir 17 sementes por metro, a uma profundidade de aproximadamente $0,05 \mathrm{~m}$. Depois do plantio foi medida a profundidade e a distância média das sementes na linha de semeadura. Para medir a profundidade da semente, o solo foi retirado da linha de semeadura até que essas fossem encontradas, quando se mediu a distância da superfície até a semente. Em seguida, com as sementes expostas, a distância entre as sementes no sulco foi medida.

Após a passagem do conjunto trator-semeadoraadubadora foi determinada a resistência do solo à penetração na linha de semeadura, para verificar a influência da compactação da roda e do rompedor sobre o microambiente em torno da semente. A resistência do solo à penetração foi determinada em todos os tratamentos a uma profundidade de 0 a $20 \mathrm{~cm}$, utilizandose um penetrógrafo SC-60 (Asabe, 2006a, 2006b).

O índice de velocidade de emergência de plântulas foi avaliado em um comprimento de $2 \mathrm{~m}$ na linha de semeadura. A contagem das plântulas emergidas foi realizada, a cada dois dias, até os 15 dias após a semeadura. A determinação do índice de velocidade de emergência de plântulas foi realizada utilizando-se a fórmula proposta por Maguire (1962).

A fim de determinar o espaço poroso, após o plantio, foram coletadas amostras indeformadas de solo de cada parcela experimental, que deveriam conter pelo menos uma semente (Reis, 2000). Na coleta das amostras indeformadas de solo, foram construídas caixas de aço zincado com dimensões de $0,16 \times 0,08 \times 0,08 \mathrm{~m}$. As caixas foram enterradas no solo considerando-se a profundidade das sementes. No laboratório, as amostras foram secadas à sombra por 48 horas em ambiente ventilado e ao abrigo da luz. Posteriormente as amostras foram secadas em estufa, onde permaneceram a $65^{\circ} \mathrm{C}$ por 24 horas.

Cada amostra recebeu uma mistura impregnadora, previamente preparada, até $2 \mathrm{~cm}$ acima da superfície. Nessa mistura, foram utilizados $660 \mathrm{~mL}$ de resina de poliéster, $340 \mathrm{~mL}$ de estireno, $10 \mathrm{~mL}$ de catalisador da resina e 6,0 g de pigmento Uvitex (Reis, 2000).

Após a impregnação, as amostras foram deixadas novamente em ambiente sombreado e ventilado até que o solo absorvesse toda a resina. Efetuaram-se outras impregnações até que o solo estivesse completamente saturado. Nas amostras de solo impregnadas foi feito cortes em lâminas, com espessura de $5 \mathrm{~mm}$. Para a determinação do microambiente em volta da semente, as lâminas de solo foram digitalizadas, com resolução das imagens de 600 dpi. As imagens digitais foram recortadas em forma de quadrado com lados de $14,139 \mathrm{~mm}$, considerando-se o centro da semente como o centro do quadrado, representando uma área de aproximadamente $2 \mathrm{~cm}^{2}$.

O processamento das imagens para a determinação da relação solo-semente foi realizado no programa computacional Quantiporo (Fernandes Filho \& Viana, 2001).

Tabela 1. Análise química do solo na camada de 0 a $20 \mathrm{~cm}$ de profundidade.

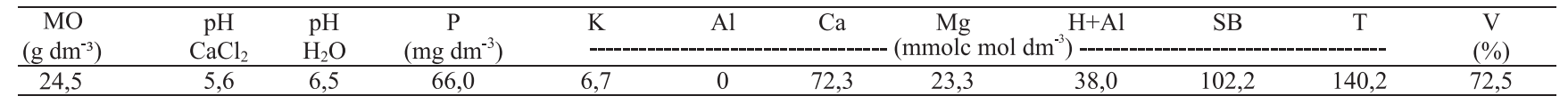


Na determinação do espaço poroso, foi feito o limiar de cada imagem, gerando os dados em porcentagem de quantidade de solo.

$\mathrm{O}$ experimento foi montado em esquema de parcelas subsubdivididas, em que as parcelas foram constituídas de três teores de água do solo $\left(0,22,0,24\right.$ e $\left.0,26 \mathrm{~kg} \mathrm{~kg}^{-1}\right)$, as subparcelas de dois mecanismos rompedores do solo (facão e disco duplo) e as subsubparcelas de três níveis de pressão aplicadas pela roda compactadora $(12,2,18,5$ e 24,1 kPa), segundo o delineamento em blocos ao acaso, com três repetições. A unidade experimental ocupou uma área de $100 \mathrm{~m}^{2}$, sendo $50 \mathrm{~m}$ de comprimento e $2 \mathrm{~m}$ de largura. Os dados obtidos foram submetidos às análises de variância e de teste de Duncan, a 5\% de probabilidade. As análises estatísticas foram realizadas utilizando-se o programa computacional SAEG, versão 9 (Ribeiro Júnior, 2001).

\section{Resultados e Discussão}

Na Tabela 2, está apresentado o resumo da análise de variância dos dados de profundidade de plantio, distância entre sementes, porosidade, índice de velocidade de emergência e emergência a campo de acordo com o teor de água do solo, tipo de mecanismo rompedor e pressão aplicada pela roda compactadora. Houve influência do teor de água do solo e do mecanismo rompedor sobre a profundidade de plantio, distância entre sementes e índice de velocidade de emergência, enquanto a porosidade do solo foi influenciada apenas pelo mecanismo rompedor e a emergência a campo foi influenciada pela interação entre rompedor e pressão aplicada ao solo pela roda compactadora.
Quando foi utilizado o rompedor do tipo facão na abertura do sulco observou-se, em média, maior profundidade de deposição de sementes (Tabela 3). Silva (2000), trabalhando com diferentes mecanismos rompedores, também verificou resultados similares. O maior valor de profundidade de deposição das sementes foi observado no teor de água do solo de $0,24 \mathrm{~kg} \mathrm{~kg}^{-1}$, independentemente do rompedor do solo usado. Reis et al. (2004), trabalhando com o mecanismo facão em um Argisolo Vermelho-Amarelo, observaram que não houve diferenças na profundidade de plantio, quanto aos teores de água de $0,22,0,28$ e $0,34 \mathrm{~kg} \mathrm{~kg}^{-1}$. Tal fato pode ser atribuído à diferenças no comportamento dos diferentes rompedores, em diferentes solos .

Ao analisar a influência do tipo de rompedor, verificouse que o disco duplo proporcionou, em média, maiores valores de distância entre sementes do que o facão (Tabela 3). O menor valor de distância entre sementes foi verificado quando o teor de água do solo era de $0,22 \mathrm{~kg} \mathrm{~kg}^{-1}$, independentemente do tipo de rompedor. Reis et al. (2004), trabalhando com semeadura direta de milho, não observaram diferenças entre o número médio de sementes distribuídas na linha de plantio por diferentes mecanismos rompedores e teores de água.

Quando foi usado o mecanismo rompedor do tipo facão, obteve-se, em média, maior porosidade do solo, $24,3 \%$ superior à alcançada quando foi usado o disco duplo (Tabela 3). Quando utilizado o disco duplo, verifica-se que não houve influência significativa do teor de água no solo sobre a porosidade. Por sua vez, quando foi usado o rompedor do tipo facão, observou-se maior porosidade do solo no menor teor de água. Esses valores de porosidade são considerados adequados (superior a $10 \%$ ) para garantir a oxigenação radicular, bem como a

Tabela 2. Resumo da análise de variância.

\begin{tabular}{|c|c|c|c|c|c|c|}
\hline \multirow[t]{2}{*}{ Fonte de variação } & \multirow[t]{2}{*}{ Grau de liberdade } & \multicolumn{5}{|c|}{ Quadrado médio } \\
\hline & & Profundidade de plantio & $\begin{array}{l}\text { Distância entre } \\
\text { sementes }\end{array}$ & Porosidade & $\begin{array}{c}\text { Índice de velocidade de } \\
\text { emergência }\end{array}$ & Emergência a campo \\
\hline Bloco & 2 & 4,705 & 3,626 & 19,808 & 0,022 & 106,699 \\
\hline Teor de água (U) & 2 & $16,256^{*}$ & $80,222 * *$ & 91,308 & $44,375^{* *}$ & 14,363 \\
\hline Erro $(\mathrm{A})$ & 4 & 4,752 & 2,671 & 30,414 & 0,023 & 14,363 \\
\hline Rompedor (R) & 1 & $4,622 * *$ & $22,828 * *$ & $253,058 *$ & 0,813 & 73,868 \\
\hline $\mathrm{U} \times \mathrm{R}$ & 2 & $1,800 * *$ & $20,586 * *$ & $239,995 *$ & $0,940 *$ & 190,827 \\
\hline Erro (B) & 6 & 0,073 & 2,018 & 58,635 & 0,206 & 225,710 \\
\hline Pressão (P) & 2 & 0,761 & 2,000 & 170,719 & 0,078 & 223,658 \\
\hline $\mathrm{U} \times \mathrm{P}$ & 4 & 0,826 & 6,628 & 17,755 & 0,330 & 94,3880 \\
\hline $\mathrm{P} \times \mathrm{R}$ & 2 & 1,061 & 12,705 & 52,009 & 0,129 & $855,647 * *$ \\
\hline $\mathrm{U} \times \mathrm{R} \times \mathrm{P}$ & 4 & 2,526 & 6,929 & 166,281 & 0,142 & 141,582 \\
\hline Resíduo & 24 & 1,588 & 4,083 & 65,496 & 0,128 & 104,647 \\
\hline $\mathrm{CV}(\%)$ & & 26,7 & 23,2 & 40,4 & 11,1 & 16,0 \\
\hline
\end{tabular}

* e **Significativo a 5 e $1 \%$ de probabilidade, respectivamente, pelo teste $\mathrm{F}$. 
capacidade de infiltração e redistribuição de água no perfil (Silva et al., 2005).

$\mathrm{O}$ aumento do teor de água do solo proporcionou diminuição do índice de velocidade de emergência, sem influência do mecanismo de abertura do solo (Tabela 3). Portella et al. (1997), estudando o efeito dos elementos de abertura do sulco e da compactação do solo, também não encontraram diferenças significativas no índice de velocidade de emergência.

O baixo índice de velocidade de emergência, correspondente ao teor de água de $0,26 \mathrm{~kg} \mathrm{~kg}^{-1}$, pode estar relacionado a uma chuva de aproximadamente $120 \mathrm{~mm}$ que ocorreu logo após a semeadura, que provocou encrostamento da camada de solo na linha de semeadura acima da semente.

Não foi verificada influência do mecanismo de abertura do sulco e da pressão aplicada ao solo sobre a emergência de plântulas em campo, quando foram analisadas separadamente (Tabela 4). Reis et al. (2004), trabalhando com milho em plantio direto, em um argisolo Vermelho-Amarelo, observou que os mecanismos de compactação não interferiram na porcentagem de emergência de plantas.
No desdobramento da interação entre mecanismo rompedor e pressão, aplicada pela roda compactadora, verifica-se que, usando o rompedor do tipo facão, a pressão de $18,5 \mathrm{kPa}$ proporcionou o menor valor de emergência em campo, enquanto não foi observada diferença significativa dentro do rompedor disco duplo (Tabela 4). Ao analisar a influência do rompedor dentro de cada nível de pressão, verifica-se que, na menor pressão, os dois mecanismos de abertura do solo apresentam valores semelhantes de emergência em campo. Embora tenha-se observado diferença na pressão intermediária quando foi usado o facão, não era de se esperar tal comportamento, uma vez que não houve diferença entre a menor e a maior pressão.

Na Figura, 1 é apresentado o comportamento da resistência do solo à penetração de acordo com a profundidade para os teores de água no perfil e mecanismos rompedores do solo. Quando o solo apresentava $0,22 \mathrm{~kg} \mathrm{~kg}^{-1}$ de teor de água, houve os maiores valores de resistência do solo à penetração. Comparando os teores de água do solo de 0,24 e $0,26 \mathrm{~kg} \mathrm{~kg}^{-1}$, pode-se verificar que, quando o solo apresentava umidade de $0,24 \mathrm{~kg} \mathrm{~kg}^{-1}$, houve maiores valores de resistência do solo à penetração até aproximadamente $15 \mathrm{~cm}$ e, a partir dessa

Tabela 3. Caracterização da semeadura de acordo com os mecanismos rompedores e do teor de água do solo ${ }^{(1)}$.

\begin{tabular}{|c|c|c|c|c|}
\hline \multirow{2}{*}{$\begin{array}{l}\text { Mecanismo } \\
\text { rompedor }\end{array}$} & \multicolumn{3}{|c|}{ Teor de água $\left(\mathrm{kg} \mathrm{kg}^{-1}\right)$} & \multirow[t]{2}{*}{ Média } \\
\hline & 0,22 & 0,24 & 0,26 & \\
\hline & \multicolumn{3}{|c|}{ Profundidade de deposição das sementes $(\mathrm{cm})$} & \\
\hline Disco duplo & $3,88 \mathrm{bB}$ & $5,31 \mathrm{aB}$ & $4,09 \mathrm{bA}$ & $4,43 \mathrm{~A}$ \\
\hline Facão & $4,80 \mathrm{bA}$ & $6,29 \mathrm{aA}$ & $3,94 \mathrm{cA}$ & $5,01 \mathrm{~B}$ \\
\hline \multirow[t]{2}{*}{ Média } & $4,34 \mathrm{ab}$ & $5,80 \mathrm{a}$ & $4,01 \mathrm{~b}$ & - \\
\hline & \multicolumn{3}{|c|}{ Distância entre sementes $(\mathrm{cm})$} & \\
\hline Disco duplo & $8,22 \mathrm{bA}$ & $10,29 \mathrm{abA}$ & $9,53 \mathrm{abA}$ & $9,35 \mathrm{~A}$ \\
\hline Facão & $4,76 \mathrm{cB}$ & $11,10 \mathrm{aA}$ & $8,29 \mathrm{bA}$ & $8,05 \mathrm{~B}$ \\
\hline \multirow[t]{2}{*}{ Média } & $6,49 \mathrm{c}$ & $10,69 \mathrm{a}$ & $8,91 \mathrm{~b}$ & - \\
\hline & \multicolumn{3}{|c|}{ Porosidade do solo (\%) } & \\
\hline Disco duplo & $20,96 \mathrm{aA}$ & $23,65 \mathrm{aA}$ & $29,75 \mathrm{aA}$ & $24,79 \mathrm{~A}$ \\
\hline Facão & $38,64 \mathrm{aB}$ & $24,74 \mathrm{bA}$ & $29,03 \mathrm{abA}$ & $30,80 \mathrm{~B}$ \\
\hline \multirow[t]{2}{*}{ Média } & $29,80 \mathrm{a}$ & $24,20 \mathrm{a}$ & $29,39 a$ & - \\
\hline & \multicolumn{3}{|c|}{ Índice de velocidade de emergência } & \\
\hline Disco duplo & $4,00 \mathrm{aA}$ & $3,73 \mathrm{aA}$ & $1,55 \mathrm{bA}$ & $3,09 \mathrm{~A}$ \\
\hline Facão & $4,62 \mathrm{aB}$ & $4,12 \mathrm{bA}$ & $1,29 \mathrm{cA}$ & $3,34 \mathrm{~A}$ \\
\hline Média & $4,31 \mathrm{a}$ & $3,93 \mathrm{~b}$ & $1,42 \mathrm{c}$ & - \\
\hline
\end{tabular}

${ }^{(1)}$ Médias seguidas por letras iguais, maiúsculas na coluna e minúsculas na linha, não diferem entre si pelo teste de Duncan, a $5 \%$ de probabilidade.

Tabela 4. Médias da emergência de plântulas a campo (\%) de acordo com a pressão exercida pela roda compactadora e do tipo de mecanismo rompedor da semeadora-adubadora ${ }^{(1)}$.

\begin{tabular}{lccc}
\hline Mecanismo rompedor & \multicolumn{3}{c}{ Pressão aplicada na linha de plantio (kPa) } \\
\cline { 2 - 4 } & 12,2 & 18,5 & 24,1 \\
\hline Disco duplo & $64,33 \mathrm{aA}$ & $66,67 \mathrm{aA}$ & $57,31 \mathrm{aA}$ \\
Facão & $70,18 \mathrm{aA}$ & $53,80 \mathrm{bB}$ & $62,77 \mathrm{~A}$ \\
\hline Média & $67,25 \mathrm{a}$ & $60,24 \mathrm{a}$ & $65,11 \mathrm{~A}$ \\
\hline
\end{tabular}

${ }^{(1)}$ Médias seguidas por letras iguais, maiúsculas na coluna e minúsculas na linha, não diferem entre si pelo teste de Duncan, a $5 \%$ de probabilidade. 

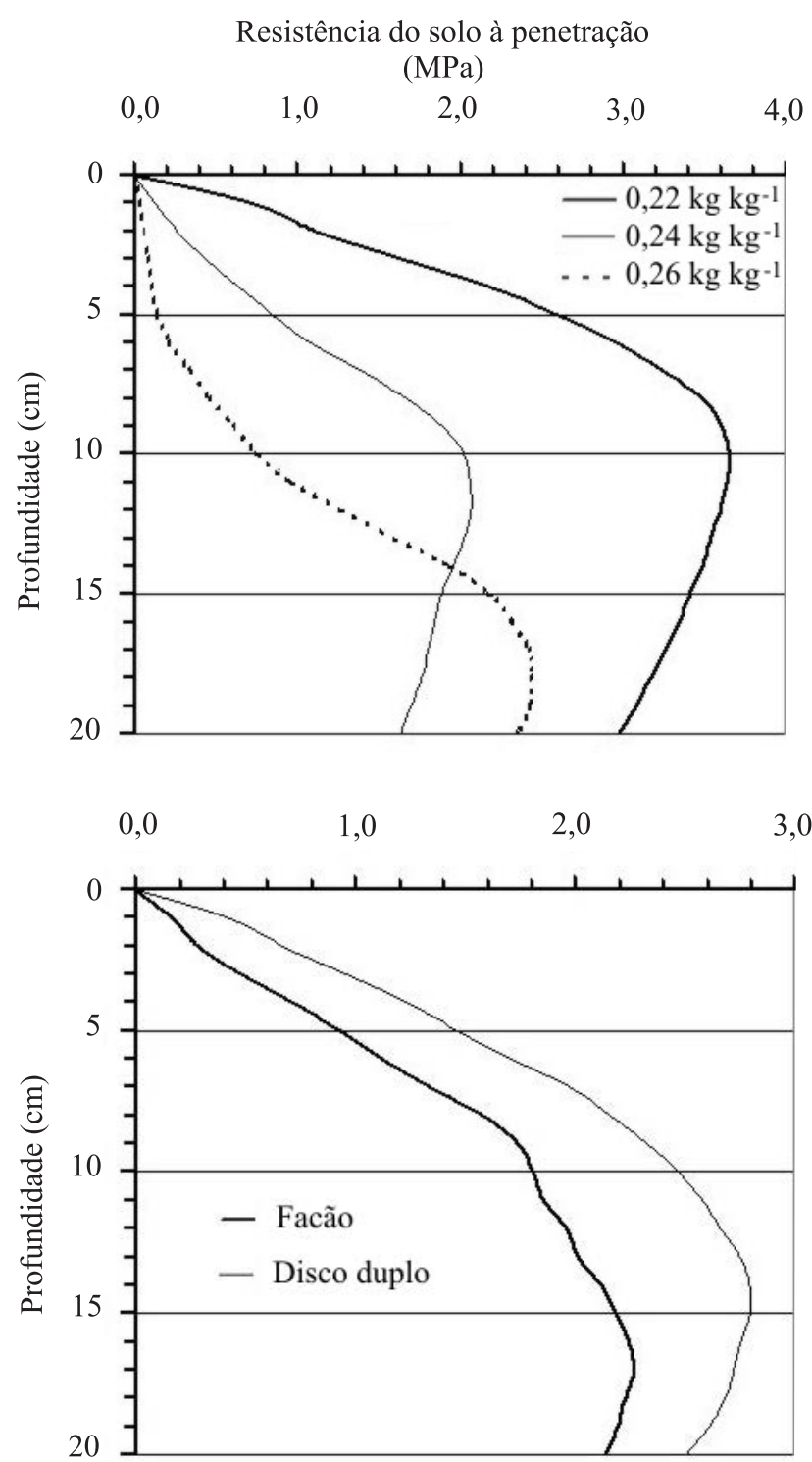

Figura 1. Resistência do solo à penetração na linha de semeadura de acordo com a profundidade do solo, para os diferentes teores de umidade e mecanismos rompedores.

profundidade, a tendência foi contrária. Resultados semelhantes foram alcançados por Reis (2003), que verificou diminuição da resistência do solo à penetração com o aumento do teor de água.

$\mathrm{O}$ uso do facão proporcionou menores valores de resistência à penetração do que o disco duplo, independentemente da profundidade do solo (Figura 1). $\mathrm{O}$ comportamento das curvas de resistência à penetração se assemelha nos dois mecanismos rompedores, sendo o facão mais efetivo na faixa de 10 a $15 \mathrm{~cm}$ de profundidade. Dados obtidos por Reis (2003), não apresentaram diferença significativa na resistência à penetração entre o facão e o disco duplo, no perfil de 0 a $10 \mathrm{~cm}$ de profundidade.

\section{Conclusões}

1. O mecanismo rompedor do tipo facão proporciona maior profundidade de deposição de sementes e porosidade do solo, menor distância entre sementes e menor resistência à penetração.

2. A pressão da roda compactadora influencia a emergência de plântulas em campo, quando é usado o rompedor do tipo facão.

3. O teor de água influencia a profundidade de deposição, distância entre sementes, o índice de velocidade de emergência e a resistência do solo à penetração.

4. Há influência do rompedor e da pressão aplicada ao solo pela roda compactadora na implantação da cultura da soja.

\section{Agradecimentos}

À Fundação de Apoio ao Desenvolvimento do Ensino, Ciência e Tecnologia do Estado de Mato Grosso do Sul, pelo suporte financeiro; à Empresa Sementes Guerra $\mathrm{ME}$, pelo apoio à pesquisa; ao $\mathrm{CNPq}$, pelas bolsas de estudo e pesquisa concedidas.

\section{Referências}

ASABE. Procedures for using and reporting data obtained with the soil cone penetrometer. In: ASABE. ASABE standards. St. Joseph, 2006b. p.1053-1055.

ASABE. Soil cone penetrometer. In: ASABE. ASABE standards. St. Joseph, 2006a. p.903-904.

EMBRAPA. Centro Nacional de Pesquisa de Solos (Rio de Janeiro, RJ). Manual de métodos de análise do solo. Rio de Janeiro, 1997. Não paginado.

FERNANDES FILHO, E.I.; VIANA, J.H.M. QUANTIPORO: um novo programa para tratamento e quantificação de imagens digitais para aplicações em ciência do solo. In: CONGRESSO BRASILEIRO DE CIÊNCIA DO SOLO, 28., 2001, Londrina. Anais. Londrina: Sociedade Brasileira de Ciência do Solo, 2001. p. 224 .

HUMMEL, J.W.; GRAY, L.E.; NAVE, W.R. Soybean emergence from field seedbed environments. Transactions of the ASAE, v.24, p.872-878, 1981. 
KONDO, M.K.; DIAS JÚNIOR, M.S. Compressibilidade de três latossolos em função da umidade e uso. Revista Brasileira de Ciência do Solo, v.23, p.211-218, 1999.

KURACHI, S.A.H.; COSTA, J.A.S.; BERNARDI, J.A.; COELHO, J.L.D.; SILVEIRA, G.M. Avaliação tecnológica de semeadoras e/ou adubadoras: tratamento de dados de ensaios e regularidade de distribuição longitudinal de sementes. Bragantia, v.48, p.249-262, 1989.

MAGUIRE, J.D. Speed of germination-aid in selection and evaluation for seedling emergence and vigor. Crop Science, v.2, p.176-177, 1962.

OLIVEIRA, M.L.; VIEIRA, L.B.; MANTOVANI, E.C.; SOUZA, C.M.; DIAS, G.P. Desempenho de uma semeadora-adubadora para plantio direto, em dois solos com diferentes tipos de cobertura vegetal. Pesquisa Agropecuária Brasileira, v.35, p.1455-1463, 2000.

PORTELLA, J.A.; SATLER, A.; FAGANELLO, A. Índice de emergência de plântulas de soja e de milho em semeadura direta no Sul do Brasil. Engenharia Agrícola, v.17, p.71-78, 1997.

QUEIROZ-VOLTAN, R.B.; NOGUEIRA, S.S.S.; MIRANDA, M.A.C. Aspectos da estrutura da raiz e do desenvolvimento de plantas de soja em solos compactados. Pesquisa Agropecuária Brasileira, v.35, p.929-938, 2000.

REIS, E.F. dos. Ambiente solo-semente em um Latossolo Vermelho-Amarelo com diferentes mecanismos rompedores e compactadores de uma semeadora de plantio direto na cultura do milho. 2003. 66p. Tese (Doutorado) - Universidade Federal de Viçosa, Viçosa.
REIS, E.F. dos. Inter-relação solo-semente com duas semeadorasadubadoras de plantio direto, em diferentes umidades de um solo argiloso. 2000. 51p. Dissertação (Mestrado) - Universidade Federal de Viçosa, Viçosa.

REIS, E.F. dos; CUNHA, J.P.A.; FERNANDES, H.C.; RONDÓN, P.P. Influência de mecanismos rompedores de solo no desempenho de uma semeadora-adubadora de plantio direto. Revista Ciencias Técnicas Agropecuarias, v.12, p.1-6, 2003.

REIS, E.F. dos; FERNANDES, H.C.; SCHAEFER, C.E.G.R.; ARAÚJO, E.F. Avaliação de mecanismos rompedores e compactadores em semeadura direta. Revista Engenharia na Agricultura, v.12, p.212-221, 2004.

REIS, E.F. dos; SCHAEFER, C.E.G.R.; FERNANDES, H.C.; NAIME, J. de M.; ARAÚJO, E.F. Densidade do solo no ambiente solo-semente e velocidade de emergência em sistema de semeadura de milho. Revista Brasileira de Ciência do Solo, v.30, p.777-786, 2006.

RIBEIRO JÚNIOR, J.I. Análises estatísticas no SAEG. Viçosa: Editora UFV, 2001. 301p.

SILVA, M.A.S.; MAFRA, A.L.; ALBUQUERQUE, J.A.; BAYER, C.; MIELNICZUK, J. Atributos físicos do solo relacionados ao armazenamento de água em um Argissolo Vermelho sob diferentes sistemas de preparo. Ciência Rural, v.35, p.544-552, 2005.

SILVA, S.L. Avaliação de semeadoras de plantio direto: demanda energética, distribuição longitudinal e profundidade de deposição de sementes em diferentes velocidades de deslocamento. 2000. 123p. Tese (Doutorado) - Universidade Estadual Paulista, Botucatu. 